\title{
Work-Related Low Back Pain Treatment: A Randomized Controlled Trial from Tehran, Iran, Comparing Multidisciplinary Educational Program versus Physiotherapy Education
}

\author{
Leila Ghadyani ${ }^{1}$, Sedigheh Sadat Tavafian ${ }^{1}$, Anoshirvan Kazemnejad ${ }^{2}$, Joan Wagner ${ }^{3}$ \\ ${ }^{1}$ Department of Health Education, Faculty of Medical Sciences, Tarbiat Modares University, Tehran, Iran \\ ${ }^{2}$ Department of Statistics, Faculty of Medical Sciences, Tarbiat Modares University, Tehran, Iran \\ ${ }^{3}$ Faculty of Nursing, University of Regina, Regina, SK, Canada
}

\begin{abstract}
Study Design: Clinical trial.
Purpose: To compare the multidisciplinary educational program versus physiotherapy education among Iranian nurses.

Overview of Literature: Low back pain (LBP) can accompany significant occupational injuries in the nursing profession. There is no agreement on the most effective educational practice.

Methods: This study was conducted from August 17, 2014 to September 22, 2014 in Tehran, Iran. Eligible nurses with chronic mechanical LBP $(n=136)$ were classified into an intervention group $(n=66)$ or the control group $(n=70)$. The intervention group received physiotherapy education for 120-minutes followed by a 120-minute health education session based on predictive constructs of social cognitive theory (SCT). The control group received the 120-minute physiotherapy education. Disability rate, pain severity and back pain prevention behavior were measured at initially and 3 months after intervention using visual analogue scale, Roland-Morris disability questionnaire and nursing low back pain preventive behaviors questionnaire.

Results: The two groups were the same in terms of all studied variables at the initiation of the study. At the 3-month follow up, predictive constructs of LBP preventive behaviors of participants in the intervention were improved $(p<0.001)$. Significant decreases were evident at 3 months in pain severity $(p=0.03)$ and disability $(p=0.003)$.

Conclusions: The designed multidisciplinary educational intervention could decrease chronic mechanical LBP in nurses.
\end{abstract}

Keywords: Chronic mechanical low back pain; Social cognitive theory; Physiotherapy; Nursing staff

\section{Introduction}

Low back pain (LBP) is the second-leading health problem concerning disability and visits to the doctor in people under 45 years of age [1]. Musculoskeletal dis- orders including LBP comprise significant occupational injuries and disability within the nursing profession [1]. One research study showed that $11 \%$ of nurses quit their job because of LBP [2]. LBP is reportedly the most important reason for nurses' decisions to change their jobs [3,4].

\footnotetext{
Received Nov 8, 2015; Revised Dec 1, 2015; Accepted Revised Dec 1, 2015

Corresponding author: Sedigheh Sadat Tavafian

Department of Health Education, Faculty of Medical Sciences, Tarbiat Modares University, Tehran 14115-331, Iran

Tel: +98-21-82884547, Fax: +98-21-82884555, E-mail: tavafian@modares.ac.ir
} 
Back injuries are a major cause of pain suffering, disability, high medical costs and absence from work among nurses [5].

A multidisciplinary program involving two or more targeted interventions has been reported to be successful at significantly decreasing chronic back pain, compared with a monodisciplinary approach [6-8]. Multi-dimensional exercise training is useful for reducing LBP by helping to alleviate fear avoidance beliefs. Excessive fear of heightened disability is an obstacle for recovery from acute, sub acute, and chronic LBP [1].

Health promotion measures in many countries create a supportive environment and can beneficially affect macroeconomic health policy [9]. However, in some countries the importance of health promotion for nurses is less recognized [10]. It appears that Iran is among the latter group.

Social cognition is an important cognitive concept recognized in recent decades as being important in the understanding of human healthy behaviors. This kind of cognition is reflexive, participatory and involves conciliatory behaviors [11]. Behavior is affected by learning, which is in turn influenced by societal models. Consequently, modifying environmental conditions, ensuring efficient self-care and improving inter-personnel relationships are among the most important methods to enhance health [12].

Social cognitive theory (SCT) provides a comprehensive and well-supported conceptual framework consisting of constructs including knowledge, outcome expectations, outcome expectancies, situational perception environment, self-efficiency, self efficacy in overcoming impediments, goal setting or self-control, and emotional coping, which can be used to understand factors that influence human behavior and the processes through which learning occurs, offering insight into a wide variety of healthrelated issues. Greater significance of SCT has come from its application to the design of interventions to meet important practical challenges in medicine and public health [11]. Each of the aforementioned constructs can contribute to predicting the implementation of preventive behaviors [12]. Thus, behavior can be changed through new learning experiences, guidance in the adjustment of perceptions, and support for the development of capacities [1].

In this study, SCT was used to assess preventive behaviors regarding mechanical chronic LBP. The aim was to use SCT to drive social learning [13]. The study compared the effect of a multidisciplinary educational approach based on SCT and physiotherapy with physiotherapy alone on the alleviation of chronic mechanical LBP among nurses.

\section{Materials and Methods}

This was a clinical trial. The statistical sample consisted of nurses with chronic mechanical LBP working in Mostafa Khomeini Hospital, Tehran, Iran. Eligible nurses were classified into two groups: an intervention group comprising 66 participants and a control group comprising 70 participants. Inclusion criteria were age 18 years and older and presence of mechanical LBP for more than 90 days. Exclusion criteria included spinal surgery within the past 2 years, congenital abnormalities in the spine, pregnancy, inflammation or presence of spine tumor. Questionnaires were presented to each of the participants and they were asked to complete it anonymously.

The intervention group received a physiotherapy educational program plus a health educational program based on SCT predictive constructs of emotional coping, environment, self-efficacy, and self-efficacy in overcoming impediments in the working environment. The control group received just the physiotherapy educational program. The physical therapy training session for both groups was provided by the same physiotherapist. In the 120-minute session the participants were educated regarding protecting healthy postures of vertebra while daily activities as well as appropriate back exercise training, through role-play and viewing related slides. Participants in intervention group engaged in the same 120-minute session delivered by the same physiotherapist, followed by another 120-minute session of health education in which a specialist addressed emotional coping, environment perception and self-efficacy in overcoming impediments in the working environment. The session involved preventive behaviors and exercises, group discussion, question and answer time and a motivational interview. The goal of the health education was to motivate participants to adopt healthy behaviors and practices in their work site.

Three questionnaires were used in this study. The Nursing low back pain predictor questionnaire (NLBPPQ) was used to measure predictive constructs of SCT. The development and psychometric process of this instrument as well as its' validity and reliability have been reported [14]. 
An established and validated visual analogue scale (VAS) was used to measure pain severity. The VAS is a psychometric response scale that can be used in questionnaires as a measurement instrument for subjective characteristics or attitudes that cannot be directly measured. When responding to a VAS item, respondents specify their level of agreement to a statement by indicating a position along a continuous line between two end-points of zero and 10 $[15,16]$.

The Roland-Morris Disability Questionnaire (RDQ) is most sensitive for patients with mild to moderate disability due to acute, sub-acute or chronic LBP. The questionnaire measures restriction or lack of ability to perform daily activities [17]. The validity and reliability of this instrument has been reported $[18,19]$.

All data were collected at the beginning of the study and at the 3-month follow-up. All comparisons between the two groups in terms of demographic characteristics were done by chi-square test. The two groups were compared in terms of SCT constructs, VAS and RMQ scale score through Student's $t$-test. Paired $t$-test was used to compare both groups before and after intervention. The Ethic Committee of Tarbiat Modares University approved the study.

\section{Results}

A total of 136 nurses with chronic mechanical LBP were studied. Sixty-six nurses received the multidisciplinary intervention program and 70 nurses received the physiotherapy educational program. Forty nine participants (74.2\%) in the intervention group and fifty participants (71.4\%) in the control group were female. Demographic characteristics are shown in Table 1. The mean scores of SCT predictive constructs regarding LBP preventive behaviors are shown in Table 2. All predictive factors in the intervention group were improved after 3 months (all $p<0.001)$. Table 3 presents the mean scores of pain severity, disability, and preventive behaviors of the two groups. In the intervention group, pain severity was significantly reduced at the 3-month follow up ( $p=0.03)$ and disability was decreased $(p=0.003)$.

\section{Discussion}

This study was conducted to compare the effects of a physiotherapy educational program alone (control) or in combination with a health educational program based on predictive constructs of SCT (intervention) on reduction of LBP severity and disability in nurses. The intervention program significantly reduced pain severity compared with the control group. This improvement might have reflected the success of the SCT-based intervention in promoting healthy behaviors. The general self-efficacy of the participants and their ability to overcoming impediments in their working environment were improved after 3 months of intervention.

The results indicated multifaceted training involving physical therapy based on SCT improved mediator variables, such as predicting constructs that significantly reduced pain and disability in the intervention group. In the control group, who received just the physical training, these improvements were not evident. Thus, it seems physical training in the context of SCT constructs could have better and continued results regarding pain reduction and disability improvement.

Consistent with the present findings, Plotnikoff et al. [20] reported in a study of 1717 adults that a SCT-based educational intervention could predict $59 \%$ of the physical activity behavior variance among their participants. The present results are also consistent with another study healthier behavior in participants receiving a SCT-based intervention [21].

The mechanism of SCT in promoting behavior has been reported [12]. The present results reinforced prior reports as the success of multidisciplinary programs in reducing the disability of the participants compared to the typical monodisciplinary approach of care $[8,22]$. Therefore, multidisciplinary treatment (such as physiotherapy education+SCT-based educational in the present study) appears to be much more effective than a physiotherapy educational program alone for decreasing LBP severity and disability. The collective findings indicate that the success of the intervention program may be due to continued motivation of the participants to cope with preventive behavior change regarding LBP. Participants in intervention group were encouraged to cope with their working environment and developed confidence that they could overcome workplace impediments. Participants in physiotherapy educational program only received education regarding healthy behaviors and proper exercise.

Also consistent with these results, Petit et al. [23] reported the benefits of a mixed and lighter intensive multidisciplinary strategy on disability and pain reduc- 
Table 1. Demographic characteristics of both studied groups at initial of the study

\begin{tabular}{|c|c|c|c|}
\hline Background variables & Control (\%) & Intervention (\%) & $p$-value $\left(\chi^{2}\right)$ \\
\hline Sex & & & 0.431 \\
\hline $\begin{array}{l}\text { Man } \\
\text { Female }\end{array}$ & $\begin{array}{l}20(28.6) \\
50(71.4)\end{array}$ & $\begin{array}{l}17(25.8) \\
49(74.2)\end{array}$ & \\
\hline Age (yr) & & & 0.153 \\
\hline $\begin{array}{l}18-28 \\
28-38 \\
38-48 \\
\text { More than } 48\end{array}$ & $\begin{array}{c}6(8.6) \\
35(50.0) \\
27(38.6) \\
2(2.8)\end{array}$ & $\begin{array}{c}6(9.1) \\
22(33.3) \\
32(48.5) \\
6(9.1)\end{array}$ & \\
\hline Education & & & $p=0.095^{\text {a) }}$ \\
\hline $\begin{array}{l}\text { Diploma } \\
\text { Associate degree } \\
\text { Undergraduate }\end{array}$ & $\begin{array}{l}24(34.3) \\
20(28.6) \\
26(37.1)\end{array}$ & $\begin{array}{l}20(30.3) \\
18(27.3) \\
28(42.4)\end{array}$ & \\
\hline Marital status & & & 0.346 \\
\hline $\begin{array}{l}\text { Single } \\
\text { Married }\end{array}$ & $\begin{array}{l}19(27.1) \\
51(72.9)\end{array}$ & $\begin{array}{l}15(22.7) \\
51(77.3)\end{array}$ & \\
\hline Shifts & & & 0.708 \\
\hline $\begin{array}{l}\text { Morning } \\
\text { Evening } \\
\text { Night } \\
\text { Rotating }\end{array}$ & $\begin{array}{c}8(11.4) \\
3(4.3) \\
16(22.9) \\
43(61.4)\end{array}$ & $\begin{array}{r}12(18.2) \\
2(3.03) \\
13(19.7) \\
39(59.1)\end{array}$ & \\
\hline Employment status & & & 0.219 \\
\hline $\begin{array}{l}\text { Official } \\
\text { Official test } \\
\text { Contract } \\
\text { Contractual }\end{array}$ & $\begin{array}{c}41(58.6) \\
3(4.3) \\
24(34.3) \\
2(2.9)\end{array}$ & $\begin{array}{c}44(66.7) \\
5(7.6) \\
13(19.7) \\
4(6.1)\end{array}$ & \\
\hline Duration of service (yr) & & & 0.624 \\
\hline $\begin{array}{l}1-5 \\
5-10 \\
10-15 \\
15-20 \\
\text { More than } 20\end{array}$ & $\begin{array}{r}15(21.4) \\
16(22.9) \\
24(34.3) \\
8(11.4) \\
7(10.0)\end{array}$ & $\begin{array}{r}11(16.7) \\
16(24.2) \\
18(27.3) \\
13(19.7) \\
8(12.1)\end{array}$ & \\
\hline \multicolumn{4}{|l|}{ Work per week (hr) } \\
\hline $\begin{array}{l}\text { Less than } 40 \\
40-50 \\
50-60 \\
\text { More than } 60\end{array}$ & $\begin{array}{r}14(20.0) \\
32(45.7) \\
7(10.0) \\
17(24.3)\end{array}$ & $\begin{array}{l}10(15.2) \\
35(50.03) \\
12(18.2) \\
9(13.6)\end{array}$ & \\
\hline Term low back pain (yr) & & & 0.680 \\
\hline $\begin{array}{l}1-5 \\
5-10 \\
\text { More than } 20\end{array}$ & $\begin{array}{c}47(67.1) \\
18(25.7) \\
5(7.1)\end{array}$ & $\begin{array}{c}41(62.1) \\
20(30.3) \\
5(7.6)\end{array}$ & \\
\hline Body mass index & & & 0.462 \\
\hline $\begin{array}{l}18 \text { Less than } \\
24.9-18.5 \\
29.9-25 \\
\text { More than } 30\end{array}$ & $\begin{array}{c}- \\
31(44.3) \\
30(42.3) \\
10(12.9)\end{array}$ & $\begin{array}{c}1(1.5) \\
33(50.0) \\
27(40.9) \\
5(7.6)\end{array}$ & \\
\hline
\end{tabular}

a) Mann-Whitney. 
Table 2. Comparing mean scores of predictive constructs in both groups at initial of the study and 3-month follow-up

\begin{tabular}{|c|c|c|c|c|c|c|}
\hline \multirow{2}{*}{ Variable } & \multicolumn{3}{|c|}{ Control group } & \multicolumn{3}{|c|}{ Intervention group } \\
\hline & Before & After & $p$-value & Before & After & $p$-value \\
\hline Emotional coping & $2.30(0.707)$ & $2.33(0.719)$ & 0.701 & $2.11(0.685)$ & $3.45(0.719)$ & $<0.001$ \\
\hline Environment & $2.66(0.666)$ & $2.6(0.644)$ & 0.513 & $2.09(0.547)$ & $3.15(0.469)$ & $<0.001$ \\
\hline Self-efficacy in overcoming & $2.54(0.600)$ & $2.39(0.520)$ & 0.070 & $2.22(0.576)$ & $2.95(0.652)$ & $<0.001$ \\
\hline Self-efficacy & $2.30(0.711)$ & $2.37(0.727)$ & 0.418 & $1.95(0.62)$ & $2.30(0.723)$ & $<0.001$ \\
\hline
\end{tabular}

Values are presented as mean \pm standard deviation.

Table 3. Comparing preventive behaviors, pain severe and disability rate of intervention and control group at initial of the study and 3-month follow-up

\begin{tabular}{|c|c|c|c|c|c|c|}
\hline \multirow{2}{*}{ Variable } & \multicolumn{3}{|c|}{ Control group } & \multicolumn{3}{|c|}{ Intervention group } \\
\hline & Before & After & $p$-value & Before & After & $p$-value \\
\hline Pain sever (VAS score) & $4.47(1.442)$ & $4.37(1.395)$ & 0.706 & $4.11(1.500)$ & $4.56(1.530)$ & $<0.001$ \\
\hline Disability (RDO score) & $6.37(2.772)$ & $6.51(2.972)$ & 0.768 & $5.95(2.616)$ & $7.08(3.457)$ & $<0.001$ \\
\hline Preventive behaviors score & $13.63(2.445)$ & $14.17(2.246)$ & 0.068 & $17.02(2.72)$ & $14.41(2.474)$ & $<0.001$ \\
\hline
\end{tabular}

Values are presented as mean \pm standard deviation.

VAS, visual analogue scale; RDQ, Ronald-Morris Disability Questionnaire.

tion compared to two other approaches like intensive hospital-based program and outpatient program [23]. Furthermore, it has been argued that to effectively treat chronic pain patients, functional restoration program as well as psychosocial support programs are necessary [22]. The current results are consistent with results from other studies [24-27] in which the reduction of pain severity and disability rate were observed after intervention. Furthermore, a previous study reported better effects of multidisciplinary group rehabilitation versus individual physiotherapy for chronic nonspecific LBP reduction [28].

Lack of social support in the health system in Iran is a reality. The present study addresses psychological, biological, and social aspects of chronic pain. The role of health education specialist during this study was of crucial value, and is an aspect of the health system worth bolstering. The benefits of motivation and social support in improving outcomes in patients with chronic LBP have been reported [29].

As with most research, there are some limitations in this study that could have affected the findings. There were no data regarding the use of other resources. Secondly, the data were self-reported. However, the findings are consistent with previous data that have indicated the value of multidisciplinary treatment for LBP.

\section{Conclusions}

Physiotherapy training that integrates education based on SCT can lead to significantly better results concerning health behavior changes and reduction of pain and disability among nurses suffering from chronic LBP.

\section{Conflict of Interest}

No potential conflict of interest relevant to this article was reported.

\section{Acknowledgments}

The financial support of the Research Deputy of Tarbiat Modares University is gratefully acknowledged. The author would like to thank them for this financial support.

\section{References}

1. Abedini R, Choobineh A, Hasanzadeh J. Musculoskeletal load assessment in hospital nurses with patient transfer activity. Int J Occup Hyg 2013;5:39-45.

2. Punnett L, Wegman DH. Work-related musculoskeletal disorders: the epidemiologic evidence and the 
debate. J Electromyogr Kinesiol 2004;14:13-23.

3. Karahan A, Bayraktar N. Determination of the usage of body mechanics in clinical settings and the occurrence of low back pain in nurses. Int J Nurs Stud 2004;41:67-75.

4. Bagwell MM, Bush HA. Improving health promotion for blue-collar workers. J Nurs Care Qual 2000;14:6571.

5. Trinkoff AM, Lipscomb JA, Geiger-Brown J, Storr CL, Brady BA. Perceived physical demands and reported musculoskeletal problems in registered nurses. Am J Prev Med 2003;24:270-5.

6. Keedy NH, Keffala VJ, Altmaier EM, Chen JJ. Health locus of control and self-efficacy predict back pain rehabilitation outcomes. Iowa Orthop J 2014;34:15865.

7. Vollenbroek-Hutten MM, Hermens HJ, Wever D, Gorter M, Rinket J, Ijzerman MJ. Differences in outcome of a multidisciplinary treatment between subgroups of chronic low back pain patients defined using two multiaxial assessment instruments: the multidimensional pain inventory and lumbar dynamometry. Clin Rehabil 2004;18:566-79.

8. Tavafian SS, Jamshidi AR, Mohammad K. Treatment of chronic low back pain: a randomized clinical trial comparing multidisciplinary group-based rehabilitation program and oral drug treatment with oral drug treatment alone. Clin J Pain 2011;27:811-8.

9. Hsiao YC, Chen MY, Gau YM, Hung LL, Chang SH, Tsai HM. Short-term effects of a health promotion course for Taiwanese nursing students. Public Health Nurs 2005;22:74-81.

10. Cleary M, Walter G. Towards a healthier lifestyle for staff of a psychiatric hospital: description of a pilot programme. Int J Ment Health Nurs 2005;14:32-6.

11. Elder JP, Ayala GX, Harris S. Theories and intervention approaches to health-behavior change in primary care. Am J Prev Med 1999;17:275-84.

12. McAlister AL, Perry CL, Parcel GS. How individuals, environments, and health behaviors interact social cognitive theory. In: Glanz K, Rimer BK, Viswanath $\mathrm{K}$, editors. Health behavior and health education: theory, research and practice. San Francisco: JosseyBass; 2008. p.176-88.

13. Bandura A. Social learning theory. Englewood Cliffs (NJ): Prentice Hall; 1977.

14. Ghadyani L TS, Kazemnejad A, wagner J. The effect of a theory-based educational intervention on promoting prevention of chronic mechanical low back pain in nursing staff [dissertation]. Tehran: Tarbiat Modares University; 2016.

15. Keefe FJ, Rumble ME, Scipio CD, Giordano LA, Perri LM. Psychological aspects of persistent pain: current state of the science. J Pain 2004;5:195-211.

16. Price DD, McGrath PA, Rafii A, Buckingham B. The validation of visual analogue scales as ratio scale measures for chronic and experimental pain. Pain 1983;17:45-56.

17. Deyo RA, Battie M, Beurskens AJ, et al. Outcome measures for low back pain research. A proposal for standardized use. Spine (Phila Pa 1976) 1998;23: 2003-13.

18. Ostelo RW, Deyo RA, Stratford P, et al. Interpreting change scores for pain and functional status in low back pain: towards international consensus regarding minimal important change. Spine (Phila Pa 1976) 2008;33:90-4.

19. Roland M, Fairbank J. The Roland-Morris Disability Questionnaire and the Oswestry Disability Questionnaire. Spine (Phila Pa 1976) 2000;25:3115-24.

20. Plotnikoff RC, Lippke S, Courneya KS, Birkett N, Sigal RJ. Physical activity and social cognitive theory: a test in a population sample of adults with type 1 or type 2 diabetes. Appl Psychol 2008;57:628-43.

21. Dunlop NL. Using social cognitive theory to identify key determinants of physical activity in people living with multiple sclerosis [dissertation]. Ottawa: University of Ottawa; 2006.

22. Tavafian SS, Jamshidi AR, Mohammad K. Treatment of low back pain: randomized clinical trial comparing a multidisciplinary group-based rehabilitation program with oral drug treatment up to 12 months. Int J Rheum Dis 2014;17:159-64.

23. Petit A, Roche-Leboucher G, Bontoux L, et al. Effectiveness of three treatment strategies on occupational limitations and quality of life for patients with nonspecific chronic low back pain: is a multidisciplinary approach the key feature to success: study protocol for a randomized controlled trial. BMC Musculoskelet Disord 2014;15:131.

24. Cairns MC, Foster NE, Wright C. Randomized controlled trial of specific spinal stabilization exercises and conventional physiotherapy for recurrent low back pain. Spine (Phila Pa 1976) 2006;31:E670-81. 
25. van Middelkoop M, Rubinstein SM, Kuijpers T, et al. A systematic review on the effectiveness of physical and rehabilitation interventions for chronic nonspecific low back pain. Eur Spine J 2011;20:19-39.

26. Hurley DA, O'Donoghue G, Tully MA, et al. A walking programme and a supervised exercise class versus usual physiotherapy for chronic low back pain: a single-blinded randomised controlled trial. (The $\mathrm{Su}-$ pervised Walking In comparison to Fitness Training for Back Pain (SWIFT) Trial). BMC Musculoskelet Disord 2009;10:79.

27. Mannion AF, Muntener M, Taimela S, Dvorak J. Comparison of three active therapies for chronic low back pain: results of a randomized clinical trial with one-year follow-up. Rheumatology (Oxford) 2001;40: 772-8.

28. Kaapa EH, Frantsi K, Sarna S, Malmivaara A. Multidisciplinary group rehabilitation versus individual physiotherapy for chronic nonspecific low back pain: a randomized trial. Spine (Phila Pa 1976) 2006; 31:371-6.

29. Vong SK, Cheing GL, Chan F, So EM, Chan CC. Motivational enhancement therapy in addition to physical therapy improves motivational factors and treatment outcomes in people with low back pain: a randomized controlled trial. Arch Phys Med Rehabil 2011;92:176-83. 